\title{
Screening of Congenital Heart Disease in Newborns by Physical Examination and Pulse Oximetry in a Tertiary Care Center in Western Maharashtra
}

\author{
Dr. Snehal Satish Surana ${ }^{1}$, Dr. Chandrashekhar Aundhakar ${ }^{2}$
}

\begin{abstract}
Objectives: To detect Congenital Heart Diseases (CHD) at an early stage and to find out its occurrence in asymptomatic healthy term newborns. To assess the role of pulse oximetry as a screening tool in CHD. Methods: All apparently healthy newborns delivered in a period of 1 year in Krishna Institute of Medical Sciences, Karad were screened for the presence of CHD by physical examination and pulse oximetry recording in pre-ductal and post-ductal limbs on three occasions. Results: Out of 2761 neonates screened, 23 were diagnosed to have CHDs; 14 were Acyanotic CHDs and 9 were Cyanotic CHDs. The occurrence of CHD was 8.3/1000 asymptomatic healthy term newborns. VSD was the most common defect followed by ASD, PDA, AV defect, TGA, Pulmonary Atresia, Pentalogy of Fallot and Severe TOF. The statistical parameters of Pulse oximetry were: Sensitivity 88.89\%, Specificity 99.02\%, Positive predictive value $22.86 \%$, Negative predictive value $99.96 \%$ and Diagnostic accuracy $98.99 \%$. Conclusion: CHDs can be detected early in asymptomatic healthy term newborns with the help of screening by physical examination and pulse oximetry assessment. Pulse oximetry can be used as an accurate, reliable, cost- effective and easy to use screening tool for detection Cyanotic CHDs.
\end{abstract}

Abstract: Congenital Heart Disease, Pulse Oximetry, Screening

\section{Introduction}

Congenital Heart Disease is one of the commonest groups of congenital malformations with an incidence of approximately 8 per 1000 live births, with a higher rate in still births ${ }^{1}$. The risk of death from congenital heart disease has decreased from $30 \%$ in the 1970 s to less than $5 \%{ }^{1}$. It contributes to $3 \%$ of all infant mortality and $46 \%$ of deaths from congenital malformations with most deaths occurring in the first year of life ${ }^{2}$.

Critical Congenital Heart Defects: CCHD is a group of heart defects that can be life threatening and require medical attention within the first few days or first year of life.

Although individually less common, when taken together, these lesions contribute significantly to death in infancy. If cardiovascular collapse occurs prior to diagnosis, death or poorer outcome following surgery is much more likely. Thus timely recognition of these cardiac defects prior to collapse is vital in order to improve outcome ${ }^{2}$.

Thus the need for an accurate, simple, non-invasive test for CHD in the early neonatal period has led to a number of investigators to examine the use of Pulse Oximetry with encouraging results. Various authors ${ }^{3,4}$ have studied the effectiveness of Pulse Oximetry as a screening tool for CHDs in otherwise asymptomatic newborns and have shown encouraging results with most of the studies showing good sensitivity and specificity of pulse oximetry. Most of the studies observed the newborns within 24 hours or 48 hours of life. But still the ideal age of newborn at which the screening would detect majority of CHDs with less number of false positives due to the physiological changes in the circulation after birth is yet to be decided. Thus in this study the clinical examination and pulse oximetry evaluation of the newborns is conducted on three occasions to have maximum yield of screening and detect the CHDs which may not give any clinical clue at birth.

\section{Materials \& Methods}

This was a Prospective Clinical Study conducted in the Labour room and Maternity wards of Krishna Institute of Medical Sciences, Karad. All apparently healthy newborns delivered in a period of 1 year (December 2013 to November 2014) were included in the study. Sample size 2761 newborns.

\section{Inclusion Criteria}

1) Asymptomatic (for congenital heart disease), term (gestational age $\geq 37$ weeks, as per Modified Ballard score) newborns were included in the study.

2) Informed consent given by the parents.

\section{Exclusion Criteria}

1) Preterm neonates (gestational age $<37$ weeks, as per Modified Ballard score) were excluded from the study.

2) Neonates with symptoms of presence of congenital heart disease (i.e. presence of tachypnoea, tachycardia, cyanosis, pallor, feeding difficulties, prolonged capillary refilling time) before the first examination and assessment were excluded from the study.

3) Sick neonates and neonates admitted in the NICU (neonatal intensive care unit) were excluded from the study.

4) Neonates already diagnosed as having congenital heart disease in antenatal ultrasound screening were excluded from the study.

A written and informed consent was obtained from the mother for the study and detailed information of the newborn babies was noted. Antenatal, intranatal, perinatal and family history was obtained. The newborn was then examined in detail:

Physical examination included

1) Measurement of vitals; i.e. Temperature, Heart Rate, Respiratory Rate

2) Palpation of central and peripheral pulses in all four limbs. 


\section{International Journal of Science and Research (IJSR) \\ ISSN (Online): 2319-7064 \\ Index Copernicus Value (2013): 6.14 | Impact Factor (2015): 6.391}

3) Blood pressure recordings by $\mathrm{NiBP}$

4) Complete general examination

5) Detailed systematic examination

Then the Pulse Oximetry screening was done of the newborn as per the following flow-chart on the following three occasions: <24 hours of life, 48-72 hours (Day 3) of life and 96-120 hours (Day 5) of life of the newborn.

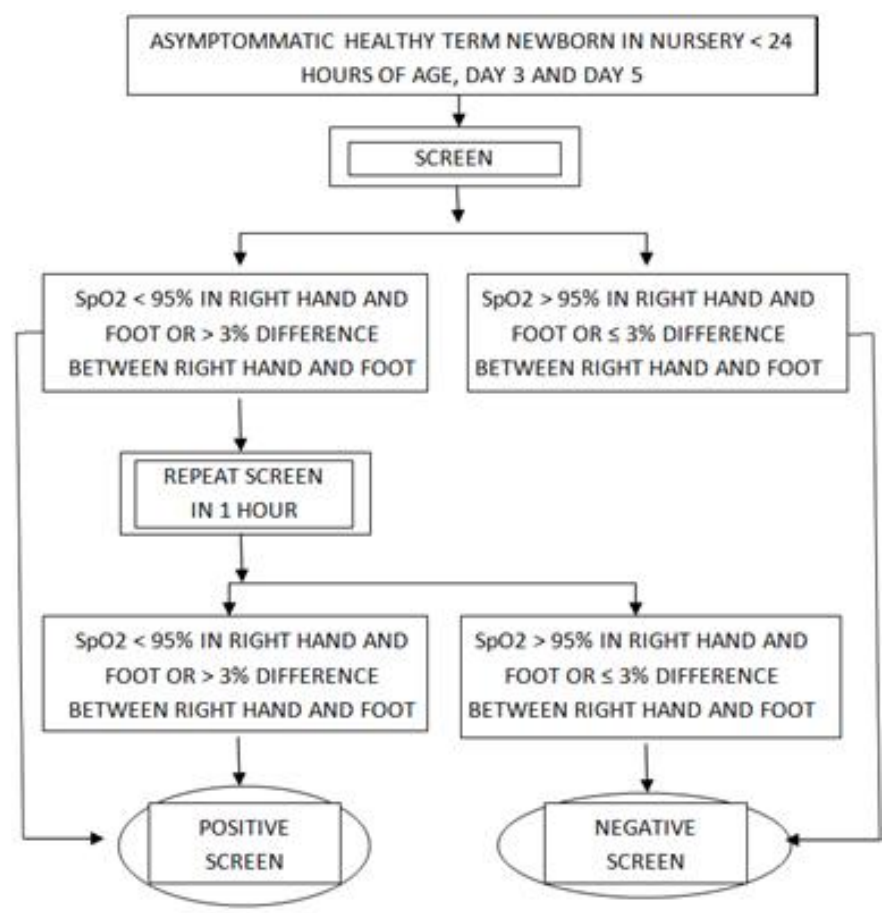

Pulse oximetry readings were taken by a pulse oximeter of EMCO company model : oxi-sat 1010, serial no : 1195238 and disposable sensor probe of Covidien company: Nellcor Neonatal SpO2 sensor. Reading taken in the right upper limb was recorded as Pre-Ductal and in the lower limb as
Post- Ductal. Pulse oximetry recordings were taken when the oximeter showed a consistent reading for 1 minute.

Neonates with recordings of $<95 \%$ on pulse oximeter or $>$ $3 \%$ difference between right hand and foot or any positive general or systemic examination finding for CHD in any of the three examinations were further investigated for the presence of congenital heart disease by performing a 2D Echocardiography. Neonates diagnosed to have CHDs were either medically managed at our centre or referred to other centers for surgical management as per the opinion of the pediatric cardiologist.

\section{Results}

Total 2761 neonates were screened for Congenital Heart Disease in this study over a period of one year. Out of 2761 neonates: 1492 were male and 1269 were female. The birth weight of $<2.5 \mathrm{~kg}$ was noted in 744 babies while 2017 had birth weight of $\geq 2.5 \mathrm{~kg}$. CHD was detected in 23 newborns out of 2761 screened. Thus the occurrence of CHD observed was 8.3/1,000 asymptomatic healthy term newborns. Table 1 and Figure 1 depict the distribution of Congenital heart diseases.

Table 1: Distribution of Cyanotic and Acyanotic Congenital Heart Diseases

\begin{tabular}{|c|c|c|}
\hline CHD & No. of Cases $\mathrm{n}=23$ & Percentage \\
\hline Acyanotic CHD & 14 & $60.87 \%$ \\
\hline Cyanotic CHD & 9 & $39.13 \%$ \\
\hline
\end{tabular}

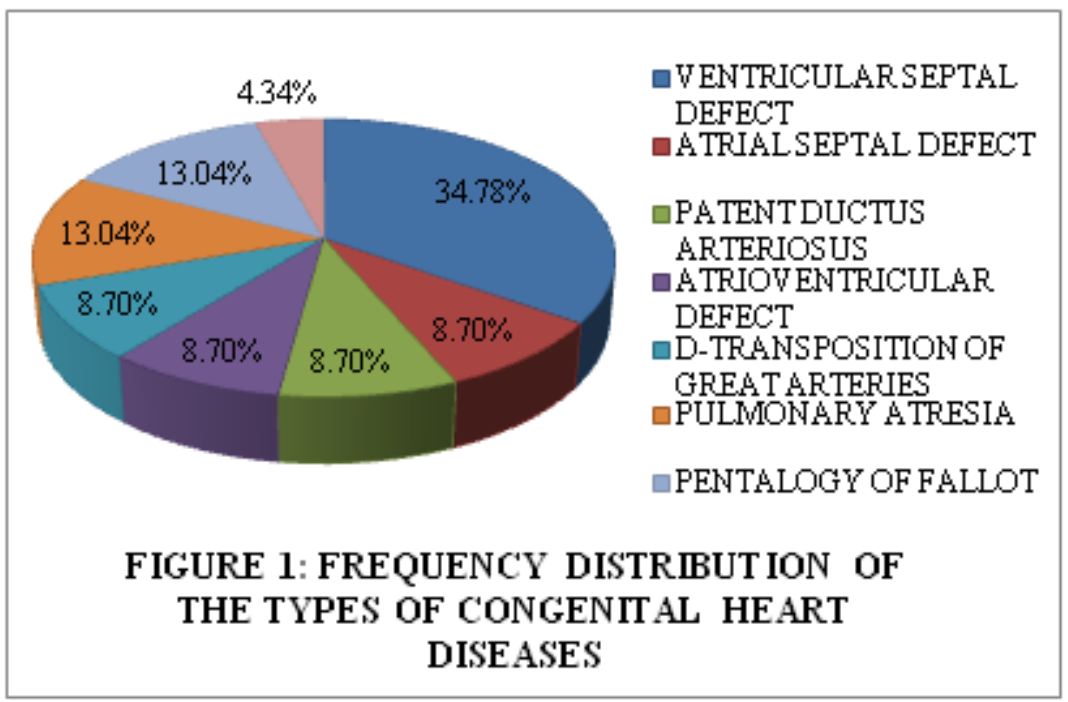

Figure 1: Frequency Distribution of the Types of Congenital Heart Diseases

Out of the 23 detected to have CHDs; 15 had birth weight of $<2.5 \mathrm{~kg}$ and 8 had birth weight of $\geq 2.5 \mathrm{~kg}$. The maternal age of 2 neonates was $<20$ years and of 2 neonates was $\geq 30$ years, while the age of rest of 21 mothers was $\geq 20$ and $<30$ years.
Significant antenatal history such as: Maternal infections like Rubella, Cytomegalovirus, HIV, Herpes, Coxsackie infection, etc or maternal illness like Diabetes Mellitus, etc or medications like anticonvulsants, lithium, retinoic acid, amphetamines, etc was noted. History of alcohol consumption, cigarette smoking or tobacco intake was taken.

\section{Volume 5 Issue 4, April 2016}




\section{International Journal of Science and Research (IJSR) \\ ISSN (Online): 2319-7064 \\ Index Copernicus Value (2013): 6.14 | Impact Factor (2015): 6.391}

Of 2761 neonates; 139 had one of the above significant antenatal history, while in the CHD group; 2 had significant antenatal history such as one had a diabetic mother and the other was a mother with epilepsy on Valproate.

Positive family history for CHD was considered if either of the parents or sibling was suffering from congenital heart disease. 11 had positive family history of heart disease. Only 1 of them was diagnosed to have CHD.

Table 2: Distribution of Age of Diagnosis of Congenital Heart Diseases By Physical Examination and Pulse Oximetry Screening

\begin{tabular}{|c|c|c|c|c|}
\hline \multirow{2}{*}{$\begin{array}{c}\text { Serial } \\
\text { No. }\end{array}$} & Type of Chd & \multicolumn{3}{|c|}{ Age of Diagnosis } \\
\cline { 3 - 5 } & & Day 1 & Day 3 & Day 5 \\
\hline 1. & Ventricular Septal Defect & 2 & 1 & 5 \\
\hline 2. & Atrial Septal Defect & 1 & & 1 \\
\hline 3. & Atrioventricular Defect & & 1 & 1 \\
\hline 4. & Patent Ductus Arteriosus & & 2 & \\
\hline 5. & D-Transposition Of Great Arteries & 2 & & \\
\hline 6. & Pulmonary Atresia & 3 & & \\
\hline 7. & Pentalogy Of Fallot & 1 & & 2 \\
\hline 8. & Severe Tetralogy Of Fallot & & 1 & \\
\hline & Total & 9 & 5 & 9 \\
\hline
\end{tabular}

\section{Age of Diagno sis of Congenital Heart Diseases by Physical Examination,Pulse Oximetry and Both}
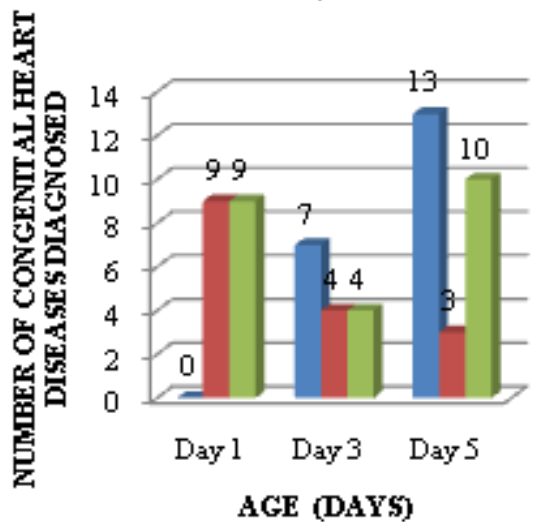

- Physical Examination

-Pulse Oximetry

\section{- Physical}

Exarination and Pulse Oximetry

Figure 2: Graphical representation of age of diagnosis of congenital heart diseases by physical examination, pulse oximetry and both

Of the 2761 neonates screened, 9 neonates had Cyanotic Congenital Heart Disease and 8 out of them were picked by Pulse Oximetry, while 1 was missed (Table 3).

27 cases were Positive on Pulse Oximetry screening but did not have Cyanotic CHD, 3 cases were of Persistent Pulmonary Hypertension, 5 cases were of Acyanotic CHD and 19 cases were False Positive cases detected by pulse oximetry screening when it was applied on neonates $<24$ hours after which the values were normal.

Table 3: Results of pulse oximetry screening for cyanotic congenital heart diseases on the neonates under the study

\begin{tabular}{|c|c|c|c|}
\hline Screening Test & \multicolumn{2}{|c|}{ Diagnostic Test } & Total \\
\cline { 2 - 3 } & Positive & Negative & \\
\hline Positive & 8 & 27 & 35 \\
\hline Negative & 1 & 2725 & 2726 \\
\hline Total & 9 & 2752 & 2761 \\
\hline
\end{tabular}

Table 4: The statistical analysis of pulse oximetry as a screening tool for detection of cyanotic congenital heart diseases

\begin{tabular}{|c|c|}
\hline Sensitivity & $88.89 \%$ \\
\hline Specificity & $99.02 \%$ \\
\hline Positive Predictive Value & $22.86 \%$ \\
\hline Negative Predictive Value & $99.96 \%$ \\
\hline Diagnostic Accuracy & $98.99 \%$ \\
\hline
\end{tabular}

\section{Discussion}

Congenital heart defects (CHD) are one of the most common birth defects. They account for about $6-10 \%$ of all infant deaths and 20-40\% deaths caused by congenital malformations ${ }^{5}$.

The reported incidence of CHD varies in different studies. It is estimated to occur in about 8-12 infants per 1000 live births (Hoffman, 2002) ${ }^{6}$. Khalil et al in $1994^{7}$ had reported an incidence of 3.9/1000 live births in hospital live births in India. Botto LD et al in $2001^{8}$ reported an incidence of 9/1000 live births. Here in our study, the occurrence of CHD was found to be $8.3 / 1000$ healthy term newborns. This figure has been rising steadily until recently when incidence of 12 to 14/1000 live births, or higher, have been reported in the literature. ${ }^{9}$ Some of the reasons for the early lower incidence rates are that only the most severely affected subjects were referred to a cardiac center, that there was relatively little interest and knowledge of CHD by pediatricians and that cardiac surgery had not yet offered the spectacular results that now demand referral of these patients. The increasing use of fetal echocardiography also leads to therapeutic abortion for complex heart diseases, and can substantially reduce the incidence of specific lesions or the total incidence as seen in study by Allan et $\mathrm{al}^{10}$. Some studies, such as by Bound et $\mathrm{al}^{11}$, deliberately excluded trivial lesions such as mild PS thus giving a low incidence. In contrast, high incidences were found in those studies that examined all or almost all newborn infants in a region, because they detected large numbers of small VSDs and other trivial lesions such as in studies by Hiraishi ei $\mathrm{al}^{12}$, Manetti et $\mathrm{al}^{13}$ and Roguin et $\mathrm{al}^{14}$. Therefore, any assessment of the incidence of CHD must take into account the age of the patients and the ways in which they entered the study.

In our study, the most common CHD diagnosed was Ventricular Septal Defect (34.78\%) followed by Pentalogy of Fallot (13.04 \%) and Pulmonary Atresia (13.04 \%), Atrial Septal Defect (8.70 \%), Patent Ductus Arteriosus (8.70 \%), Atrioventricular Defect (8.70 \%), D-Transposition of great arteries $(8.70 \%)$ and severe Tetralogy of Fallot $(4.34 \%)$ Jackson et al (1996) ${ }^{15}$ had observed VSD (36\%) as the most common CHD followed by Patent Ductus Arteriosus (9\%), Pulmonary stenosis (9\%). Indian studies on profile of Congenital heart diseases in India by Shreshtha et al $(1980)^{16}$, Vashihstha et al $(1993)^{17}$, AIIMs study in 1995 and Sharma et al (1996) ${ }^{18}$ observed most common CHD to be VSD with respective percentage of $30,41,35$ and 53 amongst the CHDs diagnosed. However, Kinare et al $(1981)^{19}$ observed most common CHD to be Tetrology of Fallot and D-TGA with 9\% of all the CHDs diagnosed. Thakur et al (1995) ${ }^{14}$ observed ASD to be most common; $38 \%$ of all CHDs diagnosed. But the above studies were 


\section{International Journal of Science and Research (IJSR) \\ ISSN (Online): 2319-7064 \\ Index Copernicus Value (2013): 6.14 | Impact Factor (2015): 6.391}

performed in children with age group ranging from 1-16 years. Only the study by AIIMS in 1995 was done in neonates, thus comparable to our study.

In our study, out of 23 diagnosed to have CHD, 12 were male and 11 were female i.e. a male to female ratio of 1.09:1. Study conducted by Daljit $\mathrm{S}$ et $\mathrm{al}^{20}$ had reported a ratio of $1: 1$, while ratios of $1.1: 1$ and $1.25: 1$ are reported from various studies in India. A. Tandon et $\mathrm{al}^{21}$ had observed higher incidence of CHD in females (53.63\%). The male to female ratio of the neonates found to have CHD in our study correlates with the findings stated above. However, a larger sample would be required to have results which could be attributed to the whole population.

Faheem et $\mathrm{al}^{22}$ (2011) and A Tandon et $\mathrm{al}^{21}$ (2010) studied the risk factors for CHD in neonates and observed low birth weight to be a significant risk factor for congenital heart disease in association with other risk factors as CHD is a multi factorial disease. Ferencz et $\mathrm{al}^{23}$ (1997) observed that individuals with lower birth weight $(<2,500 \mathrm{~g})$ were at a higher risk for the development of CHD than those with birth weight $>2,500 \mathrm{~g}$. In our study 15 out of 23 (65.22\%) of neonates diagnosed to have CHDs had birth weight of < 2500 grams. Thus our study also correlates low birth weight with presence CHD but a casual relationship cannot be established between the two.

A Tandon et $\mathrm{al}^{21}$ and Zheng et $\mathrm{al}^{24}$ observed that maternal age of $<20$ and $>30$ both are considered to be a risk factor for the development of CHD. In our study out of 23, 2 mothers had age less than 20 years and 2 were more than 30 years of age. A larger sample size would be required to attribute maternal age as a risk factor for CHDs.

A Tandon et $\mathrm{al}^{21}$ used case-control status as the dependent variable and maternal therapeutic drug exposure, maternal illness, maternal infection, as co-variates and found significant co-relation with the incidence of CHD. In our study, 2 out of the 23 neonates diagnosed to have CHD had any significant antenatal history. Significant antenatal history found in the two neonates with CHD was as followsone was a mother with Gestational Diabetes Mellitus and the other was an Epileptic mother on Valproate. The other neonates having significant antenatal history in our study did not have any co-relation with CHD.

Myung K. Park ${ }^{25}$ observed an increased risk of recurrence of $3 \%$ in a neonate with a sibling having a congenital heart disease but only one of the patients diagnosed with CHD in our study had positive family history (parents or sibling). Positive family history of CHD was observed in 11 neonates but they did not screen positive by physical examination or pulse oximetry for CHD.

Table 5: Comparison of the accuracy of pulse oximetry as a screening tool for the diagnosis of congenital heart diseases in our study with other studies

\begin{tabular}{|c|c|c|c|}
\hline Study's First Author, year & $\begin{array}{c}\text { No. of } \\
\text { patients }\end{array}$ & $\begin{array}{c}\text { Sensitivity, \% } \\
\text { (true positive } \\
\text { rate) }\end{array}$ & $\begin{array}{c}\text { Specificity, \% } \\
\text { (true negative } \\
\text { rate) }\end{array}$ \\
\hline Arlettaz, 2006 ${ }^{26}$ & 3262 & 96.9 & 99.7 \\
\hline De-Wahl Granelli, 2009' & 38429 & 62.1 & 99.8 \\
\hline
\end{tabular}

\begin{tabular}{|c|c|c|c|}
\hline Meberg, $2008^{3}$ & 50008 & 77.1 & 99.4 \\
\hline Riede, $2010^{28}$ & 41445 & 77.8 & 99.99 \\
\hline Rosati, $2005^{4}$ & 5292 & 66.7 & 100 \\
\hline Sendelbach, $2008^{29}$ & 15233 & 75 & 94.4 \\
\hline Tautz, $2010^{30}$ & 3364 & 81.8 & 99.7 \\
\hline Singh, $2014^{31}$ & 25859 & 60 & 99.2 \\
\hline Turska-Kmiec, $2012^{32}$ & 5750 & 78.9 & 99.9 \\
\hline Bhola, 2014 & 18801 & 80 & 99.8 \\
\hline Zhao, $2014^{34}$ & 120707 & 83.6 & 99.7 \\
\hline Our Study & 2761 & 88.89 & 99.02 \\
\hline
\end{tabular}

Arlettaz et al(2006) ${ }^{26}$ had screened healthy newborns $>35$ weeks at $8 \mathrm{hr}$ of life, De-Wahl Granelli $(2009)^{27}$ had screened all well babies in the nursery at a median age of 38 hrs of life, Meberg (2008) ${ }^{3}$ screened healthy newborns soon after delivery, Riede (2010) ${ }^{28}$ had screened full term healthy neonates at 24-72 hrs, Rosatti (2005) ${ }^{4}$ had screened term asymptomatic newborns at 72 hrs of life, Sendelbach $(2008)^{29}$ had screened $>35$ weeks gestation neonates at 4 hrs of life, Tautz $(2010)^{30}$ had screened $>35$ gestation weeks newborns at 6-36 hours, Singh (2014) ${ }^{31}$ screened all babies in the postnatal wards $<24$ hours of life, Turska-Kmiec $(2012)^{32}$ screened all babies at the neonatal unit between 224 hours of life, Bhola $(2014)^{33}$ had screened neonates of $>36$ weeks of gestational age at 6-72 hours of life and Zhao $(2014)^{34}$ screened all babies at 6-72 hours of life. In our study we have screened the newborns three times at preductal and post-ductal sites at $<24$ hours of life, 48-72 hours and finally $96-120$ hours of life.

Thus the results of screening with pulse oximetry in our study are comparable with studies done worldwide with comparable sensitivity and specificity. The diagnostic accuracy of Pulse oximetry as a screening tool is $98.99 \%$ thus confirming its utility in routine screening of neonates for CHD.

\section{Conclusions}

Congenital heart diseases can be detected early in asymptomatic healthy term newborns with the help of screening by physical examination and pulse oximetry assessment.

The occurrence of Congenital Heart Disease in the given population was observed to be $8.3 / 1000$ asymptomatic healthy term births.

The Sensitivity and Specificity of Pulse Oximetry as a screening tool for Cyanotic Congenital Heart Disease is $88.89 \%$ and $99.02 \%$ respectively. Thus pulse oximetry can be used an accurate, reliable, cost- effective and easy to use screening tool for detection Cyanotic CHDs.

\section{References}

[1] Denise J Kitchiner, congenital Heart Disease, Forfar \& Arneil's Textbook of Pediatrics $7^{\text {th }}$ edition, Churchill Livingstone Elsevier, 2008, pg 765-791.

[2] Ewer, R. Mupanemunda, S. Sivakumar, B.Kumararatne, S. Deshpande, P. Satodia. Pulse oximetry as a screening test for congenital heart disease in newborn babies; Protocol Version 4.1 dated 18/03/2009 


\section{International Journal of Science and Research (IJSR) \\ ISSN (Online): 2319-7064 \\ Index Copernicus Value (2013): 6.14 | Impact Factor (2015): 6.391}

[3] L J Middleton, A K Ewer, A Bhoyar, A T Furmston, J P Daniels, S Thangaratinam, J Deeks, K S Khan ; Pulse oximetry as a screening test for congenital heart defects in new born infants : the pulseox test accuracy study: Arch Dis Child Fetal Neonatal Ed 2011; pg 96

[4] Meberg A., Andreassen, A., Brunvand, L., Markestad, T., Moster, D., Nietsch, L., Silberg, I.E. and Skalevik, J.E. (2009), Pulse oximetry screening as a complementary strategy to detect critical congenital heart defects. Acta Paediatrica, 98: 682-686.

[5] Wennerholm U-B, Daxberg E-L, Fassoulas A, Hafstorm O, Liljegren A, Samuelsson O, Strandell A ; Pulse oximetry screening for congenital heart defects in newborns: Health Technology Assessment; HTA report2011:36.

[6] Hoffman JI, Kaplan S. The incidence of congenital heart disease. J Am Coll; Cardiol. 2002 Jun 19; 39(12)1890-900.

[7] A Khalil, R Aggarwal, S Thirupuram, R Arora; Incidence of Congenital heart disease among hospital live births in India, Indian Pediatrics, Volume 31, May 1994;519-527.

[8] Botto LD, Correa A, Erickson JD. Racial and temporal variations in the prevalence of heart defects. Pediatrics 2001 Mar;107(3):E32.

[9] Hoffman JIE. Incidence of congenital heart disease. I. Postnatal incidence. Pediatr Cardiol 1995; 16:103-13.

[10] Allan LD, Sharland GK, Milburn A, et al. Prospective diagnosis of 1,006 consecutive cases of congenital heart disease in the fetus.J Am Coll Cardiol 1994;23:1452-8.

[11] Bound JP, Logan WF. Incidence of congenital heart disease in Blackpool 1957-1971. Br Heart J 1977; 39:445-50.

[12] Hiraishi S, Agata Y, Nowatari M,et al. Incidence and natural course of trabecular ventricular septal defect: two-dimensional echocardiography and color Doppler flow imaging study. J Pediatr 1992; 120:409-15.

[13] Manetti A, Pollini I, Cecchi F, et al. Epidemiologia delle malformazioni cardiovascolari. III Prevalenza e decorso in 46.895 nati vivi all Maternita di Careggi, Firenze, nel periodo 1975-1984. G Ital Cardiol 1993:23;145-52.

[14] Roguin N, Du ZD, Barak M, Nasser N, Hershkowitz S, Milgram E. High prevalence of muscular ventricular septal defect in neonates. J Am Coll Cardiol 1995; 26:1545-8.

[15] Jackson M, Walsh KP, Peart I, et.al., Epidemiology of congenital heart disease in Merseyside - 1979 to 1988. Cardiol Young (1996) 6272-280.

[16] Shreshtha NK, Padmavati S; Congenital heart disease in Delhi school children. Ind J Med Res 1980,72:403-407.

[17] Vashishtha VM, Karla A, Karla K, Jain VK, Prevalance of congenital heart disease in school children: Indian Ped; 1993;30;1337-1340.

[18] Sharma M, Saxena A, Kothari SS, Reddy SCB, Prabhakaran D, Juneja R, Wasir HS; Profile of congenital heart disease: an echocardiographic study of 5000 consecutive children, Indian heart J 1996; 48:521

[19] Kinare SG, Sharma S. Congenital heart disease in first year of life (autopsy cases of 270 studies.). Indian $J$ Ped, 1981; 48:745-754
[20] Daljit S, Gurpreet S, R J Singh; Gender equality in India for children with congenital heart disease: looking for answers; heartjnl-2011-300706.

[21] Anshula Tandon, Sonali Sengupta, Vinayak Shukla and Sumita Danda, Risk Factors for congenital Heart Disease (CHD) in Vellore, India; Current Research Journal of Biological Sciences2(4):253-258, 2010.

[22] Faheem U1 Haq, Fatima Jalil, Saman Hashmi, Maliha Iqbal Jumani; risk factors predisposing to congenital heart defects; annals of pediatric cardiology;2011 Volume:4, Issue:2 Page 117-121.

[23] Ferencz, C., A. Correa-Villasenor and C.A. Loffredo, 1997. Genetic and Environmental Risk Factors of Major Cardiovascular Malformations. The BaltimoreWashington Infant study, 1981-1989. Futura Publishing Co., Armonk Ny.

[24]Zheng, X.Y., X.M. Song, G. Chen, J.P. Chen, Y. Ji, J.L.Wu, J.F.Liu, L. Zhang and X.H.fan,2007. Epidemiology of birty defects in high-prevalence areas of China. Zhongua Liu Xing Bing Xue Za Zhi., 28 (1):5-9.

[25] Myung K. Park; Part IV Specific Congenital Heart Defects, Chapter 12 to 17 in Pediatric Cardiology for Practitioners $5^{\text {th }}$ Edition, Mosby Elsevier; 2008, New Delhi. Pg 161-326.

[26] Sendelbach DM, Jackson GL, Lai SS, Fixler DE, Stehel EK, Engle WD. Pulse oximetry screening at 4 hours of age to detect critical congenital heart defects. Pediatrics 2008; 122(4) e815-20.

[27] Ellberg L, Hogberg U, Lundman B, Kallen K, Hakansson S, Lindh V. Maternity care options influence readmission of newborns. Acta Paediatr. 2008 May ; 97(5) : 579-83.

[28] Bricker L, Garda J, Henderson J, Mugford M, Neilson J, Roberts T, Martin M-A 2000 Ultrasound screening pregnancy: a systematic review of the clinical effectiveness, cost effectiveness and women's views. Health Technol Assess 4:

[29] Sharland G. Fetal Cardiac screening: why bother? Arch Dis Child Fetal Neonatal Ed. 2010 Jan; 95(1): F64-8.

[30] Tautz J, Merkel C, Loersch F, Egen O, Hagele F, Thon HM, Schaible T. Implication of pulse oxymetry screening for detection of congenital heart defects. Klin Padiatr 2010; 222(5): 291-5.

[31] Singh A, Rasiah SV, Ewer AK. The impact of routine predischarge pulse oximetry screening in a regional neonatal unit. Arch Dis Child Fetal Neonatal Ed 2014;99:F297-302.

[32] Turska Kmiec A, Borszewska Kornacka MK, Blaz W, et al. Early screening for critical congenital heart defects in asymptomatic newborns in Mazovia province: experience of the POLKARD pulse oximetry programme 2006-2008 in Poland. Kardiol Pol 2012;70:370-6.

[33] Bhola K, Kluckow M, Evans N. Post-implementation review of pulse oximetry screening of well newborns in an Australian tertiary maternity hospital. J Paediatr Child Health 2014;50:920-5.

[34]Zhao QM, Ma XJ, Ge XL, et al. Pulse oximetry with clinical assessment to screen for congenital heart disease in neonates in China: a prospective study. Lancet 2014;384:747-54. 